\title{
Sobre os objetivos, objetos e problemas da pesquisa brasileira em Modelagem Matemática na Educação Matemática
}

\section{About the aims, objects and problems in Brazilian research on Mathematical Modeling in Mathematics Education}

\author{
Tiago Emanuel Klüber* \\ Dionísio Burak ${ }^{* *}$
}

Resumo: Consideramos que toda área de pesquisa que busca se consolidar e amadurecer deve voltar-se para a própria pesquisa. Desse modo, entendemos que este trabalho é relevante para a Modelagem Matemática na Educação Matemática, pois temos a seguinte questão de pesquisa: como se mostram os objetivos, os objetos e problemas de pesquisa nas comunicações científicas publicadas na IV Conferência Nacional de Modelagem Matemática, CNMEM, realizada em 2005? Essa questão é enfrentada sob uma abordagem qualitativa do tipo meta-analítica e de conteúdo, com auxílio do software Atlas T.i. O material de coleta de dados é oriundo da referida conferência que é a primeira das três que analisaremos no estudo que visa explicitar a pesquisa em Modelagem Matemática no Brasil. As categorias estabelecidas neste artigo e que serão interpretadas são: 1) Metaestudo em Modelagem Matemática; 2) Aplicação de Modelagem; 3) Articulação entre Modelagem e outras teorias; 4) Modelagem e formação de professores.

Palavras-chave: Pesquisa. Modelagem Matemática na Educação Matemática. Metacompreensão.

\begin{abstract}
This paper presents an analysis of scientific communications published in the IV Mathematical Modeling National Conference (CNMEM in the Brazilian abbreviation), which took place in 2005 . The analysis consists of a meta-analytical and content qualitative approach, aided by the software Atlas T.i. The data collected was originated in the above mentioned conference which is the first of the three which will be analyzed in the study that aims to unveil the research on Mathematical Modeling in Brazil. The categories established in this paper and which will be interpreted are: a) Meta-study on Mathematics Modeling; b) Modeling application; c) Articulation between Modeling and other theories, and d) Modeling and teachers education.
\end{abstract}

Keywords: Research. Mathematical Modeling in Mathematical Education. Meta-comprehension.

\footnotetext{
* Professor da Universidade Estadual do Oeste do Paraná, Cascavel - PR. E-mail: <tiago_kluber@yahoo. com.br>

** Professor da Universidade Estadual do Centro-Oeste, Guarapuava - PR e professor do Programa de Pós-Graduação em Educação da Universidade Estadual de Ponta Grossa. E-mail: <dioburak@yahoo.com.br>
} 


\section{Sobre o foco de estudo}

A Modelagem Matemática na Educação Matemática tem se consolidado, no Brasil, ao longo dos últimos anos no tocante à pesquisa que sobre ela se realiza. Essa afirmação pode ser evidenciada pelos vários eventos que ocorrem no país, em diferentes estados, como no Paraná, Bahia e Pará, assim como aqueles de abrangência nacional, como o Encontro Nacional de Educação Matemática, que enfoca, em grupo específico, trabalhos sobre Modelagem Matemática, e a Conferência Nacional sobre Modelagem Matemática na Educação Matemática, evento de maior importância sobre a temática de nosso estudo. Além desses eventos de caráter misto, que envolvem relatos de experiência e pesquisas efetivamente realizadas, há o Seminário Internacional de Pesquisa em Educação Matemática, SIPEM, no qual a pesquisa sobre modelagem possui um espaço de discussão própria, no Grupo de Trabalho de número 10, GT-10.

Esses eventos indicam a presença de um grupo e talvez uma comunidade que se articula por meio da pesquisa nessa área (BARBOSA, 2007). Em outras palavras, é inegável que a pesquisa sobre ela acontece e de maneira sistemática, porém não exaustiva. Frente a essa constatação básica, a reflexão sobre o que se tem pesquisado impõe-se como uma necessidade. Dito de outro modo, é necessário empreender investigações sobre a própria pesquisa para a identificação de aspectos mais ou menos consistentes, coerentes e relevantes, buscando a reflexão e o estabelecimento de critérios acordados na comunidade, garantindo, entre outras coisas, legitimidade ao que se produz, bem como avanços nos campos científico e social.

Para sustentar o dito, recorremos ao relato da última reunião realizada pelo GT-10 de Modelagem em 2009, no âmbito do SIPEM, que, em certo sentido, ampara nossa investigação mais ampla que tem como questão central': como se mostra a pesquisa em Modelagem Matemática na Educação Matemática no Brasil? Ressaltamos, porém, que neste artigo apresentamos os resultados dessa questão dirigida, especificamente, às comunicações científicas, publicadas na IV Conferência Nacional sobre Modelagem na Educação Matemática, no tocante aos objetivos, aos objetos e problemas de pesquisa ${ }^{2}$. Em outras palavras, o problema que é enfrentado neste artigo pode ser assim sintetizado: como se mostram os objetivos, os objetos e problemas de pesquisa nas comunicações científicas publicadas na IV Conferência Nacional de Modelagem Matemática, CNMEM, realizada em 2005?

\footnotetext{
${ }^{1}$ Essa questão é uma das questões centrais do projeto de pesquisa denominado: A Modelagem Matemática no Brasil: na perspectiva da Metacompreensão. Essa pesquisa é financiada pela Fundação Araucária, agência de fomento à pesquisa em ciência e tecnologia no estado do Paraná.

${ }^{2}$ Detalhes sobre a investigação em sua totalidade serão apresentados na seção sobre os procedimentos da investigação.
} 
Ainda, de acordo com o GT-10, quatro núcleos de demandas de pesquisa emergiram a partir dos trabalhos submetidos no evento: 1) A pesquisa em Modelagem Matemática; 2) A prática dos alunos em Modelagem Matemática; 3) Reflexões filosóficas e implicações para a Modelagem; 4) Modelagem Matemática e formação de professores. Por meio da apresentação dos principais temas discutidos pelo grupo é possível pôr em destaque a investigação sobre a própria pesquisa e modos que ela se realiza e se concretiza na comunidade.

Mais especificamente, sobre a metapesquisa em Modelagem Matemática, o relatório destaca que há “[...] a necessidade de mais estudos que busquem gerar compreensões sobre o "campo de modelagem matemática", oferecendo assim subsídios para que o próprio campo possa refletir sobre seus desenvolvimentos.". (BARBOSA; CALDEIRA; ARAÚJO, 2009, p. 5-6, destaque dos autores). Essa solicitação de metaestudos, podemos assim denominar, também é apontada em âmbito internacional, antecipando, em termos teóricos, o que agora se impõe como uma necessidade para a comunidade brasileira. Aqui, cabe uma reflexão sobre o texto apresentado pelo GT de Modelagem, no tocante à expressão "refletir sobre os seus desenvolvimentos". Em nossa compreensão refletir sobre os seus desenvolvimentos supera um conotação meramente positiva, como algo que apenas progride, solicita uma reflexão sobre os modos que a produção tem se apresentado nas suas mais diversas formas, progredindo ou não.

Tendo em vista que esse relatório indica uma necessidade do campo de estudos ou comunidade, consideramos que ele, pela função aglutinante que exerce, já seria suficiente para justificar a pesquisa que estamos empreendendo. No entanto, pensamos ser também pertinente destacar o estudo realizado por Niss (2001), no qual o autor lança três questões concernentes às pesquisas sobre o ensino e a aprendizagem de aplicações e Modelagem Matemática, em âmbito internacional: 1) o que sabemos sobre essas pesquisas; 2) o que não sabemos sobre elas; e 3) as demandas gerais da pesquisa em Modelagem Matemática. Nesta terceira questão o autor apresenta dez demandas, dentre as quais destacamos aquela que solicita a concretização de "Estudos meta-analíticos em aplicações e modelagem no âmbito da Educação Matemática." (NISS, 2001, p. 80, tradução nossa ${ }^{3}$ ). Consoantes a este argumento, alguns trabalhos foram realizados recentemente, como os de Almeida (2006), Barbosa (2007), Araújo (2009) e Bicudo e Klüber (2011).

Pelo exposto, consideramos ter esclarecido a pertinência da nossa questão de pesquisa e evidenciado o seu solo histórico e contextual. A partir daqui explicitamos o modo como procedemos à investigação, bem como esclarecemos os procedimentos de coleta e análise de dados. Ressaltamos, ainda, que o modo de

${ }^{3}$ Meta-studies of applications and modelling as a domain in mathematical education. 
proceder é genérico para todo o material coletado. Por essa razão ele será descrito em caráter geral, exceto quando da apresentação das categorias estabelecidas neste estudo, em que a descrição volta a particularizar-se.

\section{Dos procedimentos da investigação}

Uma vez caracterizado o problema de pesquisa - como se mostra a pesquisa em Modelagem Matemática na Educação Matemática no Brasil? - interrogamos, em vista da questão, em que "espaços de divulgação" a pesquisa sobre Modelagem Matemática na Educação Matemática se apresenta. A partir daí identificamos os eventos e periódicos.

Os eventos delimitados pelo estudo foram aqueles específicos de Modelagem Matemática na Educação Matemática, abarcando os de caráter regional, nacional e internacional, realizados no Brasil. Frente a essas possibilidades, elegemos como significativos os eventos realizados entre o período de 2005 a 2009, como segue: 1) IV, V e VI Conferência Nacional Sobre Modelagem na Educação Matemática - CNMEM, em suas edições, realizadas em 2005, 2007 e 2009; 2) II e III Encontro Paranaense de Modelagem Matemática na Educação Matemática - EPMEM, realizados em 2006 e 2008, 3) III e IV Seminário Internacional de Pesquisa em Educação Matemática - SIPEM, grupo de trabalho de número 10, GT-10, que é referente à Modelagem Matemática na Educação Matemática, realizados em 2006 e 2009; 4) Encontro Nacional de Educação Matemática ENEM, realizado em 2007; 5) Artigos de Modelagem Matemática na Educação Matemática publicados em revistas de Educação ou Educação Matemática com qualis superior a B3, também no período de 2005 a 2009, que disponibilizassem a produção online.

Explicitados os eventos que abrigam os materiais a serem analisados, passamos ao processo de coleta e compilação dos dados. Para tanto, criamos um banco de dados com todas as comunicações científicas constantes nesses eventos e com os artigos levantados nas revistas.

Esses procedimentos estão em acordo com a posição teórica assumida em termos metodológicos: a meta-análise e a análise de conteúdo. Dessa forma, consideramos com Bardin (1977, p. 21) o sentido e os significados da análise de conteúdo nos seguintes termos:

[...] Um conjunto de técnicas de análise das comunicações, visando, por procedimentos sistemáticos e objetivos de descrição do conteúdo das mensagens, obter indicadores quantitativos ou não, que permitam a inferência de conhecimentos relativos às condições de produção/recepção (variáveis inferidas) das mensagens. 
Essa forma de tratamento dos dados se dá, conforme a mesma autora, em três etapas básicas, quais sejam: (i) a pré-análise, (ii) a descrição analítica e (iii) a interpretação inferencial. A pré-análise consiste na organização do material. A descrição analítica visa o aprofundamento do estudo sobre os documentos selecionados que constituem o corpus da pesquisa. Nesta fase ocorrem os procedimentos de codificação, de classificação e de categorização fundamentados pelo quadro referencial da pesquisa. Em nosso caso não estamos partindo de um quadro teórico definido previamente, mas de questões que são oriundas do atual quadro da pesquisa em Modelagem Matemática. Assim, estas questões constituem o quadro analítico do conteúdo. Isso não exclui o estudo dos aspectos teóricos referentes à Educação Matemática, à Modelagem Matemática, à Epistemologia e outras que se tornam necessárias.

As ações de categorização, de acordo com Franco (2005, p. 57), implicam “[...] uma operação de classificação de elementos constitutivos de um conjunto, por diferenciação seguida de um reagrupamento baseado em analogias, a partir de critérios definidos.". Esta autora, ao interpretar Bardin (1977), nos diz que tais critérios podem ser (a) semânticos - implicando categorias temáticas, (b) sintáticos - relativos aos verbos e aos adjetivos, e léxicos - atinentes à classificação das palavras segundo seu sentido.

A interpretação inferencial é a reflexão final sobre as informações dos dados empíricos, devidamente orientada pelo quadro referencial, na qual se estabelecem relações e se aprofundam conexões das ideias, podendo chegar a possíveis propostas de transformações (TRIVIÑOS, 2008).

O instrumento de categorização e análise utilizado é o software Atlas/T.i., que foi idealizado exclusivamente para a análise de dados qualitativos em grande quantidade, o que se tornou conveniente ao nosso trabalho. De acordo com o estudo realizado por Walter e Bach (2009), a primeira edição comercial do software foi lançada em 1993 na Bélgica. Desde então passou a ser utilizado em diferentes áreas do conhecimento, primeiramente por adeptos da grounded theory (teoria fundamentada nos dados ou teoria enraizada nos dados). Recentemente vem sendo empregado por pesquisadores que se valem da análise de conteúdo, em distintas vertentes. Daí a possibilidade de sua utilização nesta pesquisa. Além disso, mais recentemente, Klüber (2012) utilizou-o em sua tese, adaptando-o segundo a visão fenomenológica de pesquisa. No quadro 1 são apresentadas as principais características do software. 
Quadro 1 - Principais elementos constitutivos do Atlas/T.i

\begin{tabular}{|c|c|}
\hline Elementos & Descrição \\
\hline $\begin{array}{l}\text { Unidade hermenêutica } \\
\text { (Hermeneutic unit) }\end{array}$ & Reúne todos os dados e os demais elementos. \\
\hline $\begin{array}{l}\text { Documentos primários } \\
\text { (Primary documents) }\end{array}$ & $\begin{array}{l}\text { São os dados primários coletados. Em geral, são } \\
\text { transcrições de entrevistas e notas de campo, mas } \\
\text { suportam figuras e áudio (a versão atual também o faz } \\
\text { em relação a imagens, áudio e vídeo). Os documentos } \\
\text { primários são denominados } \mathrm{Px} \text {, sendo que x é o } \\
\text { número de ordem. }\end{array}$ \\
\hline $\begin{array}{c}\text { Citações } \\
\text { (Quotes/quotation) }\end{array}$ & $\begin{array}{l}\text { São segmentos de dados, como trechos relevantes } \\
\text { das entrevistas, ou dados em geral, que indicam } \\
\text { a ocorrência de código. A referência da citação é } \\
\text { formada pelo número do documento primário onde } \\
\text { está localizada, seguido do seu número de ordem } \\
\text { dentro do documento. Também constam da referência } \\
\text { as linhas inicial e final, no caso de texto. }\end{array}$ \\
\hline $\begin{array}{l}\text { Códigos } \\
\text { (Codes) }\end{array}$ & $\begin{array}{l}\text { São os conceitos gerados pelas interpretações do } \\
\text { pesquisador. Podem estar associados a uma citação ou } \\
\text { a outros códigos para formar uma teoria ou ordenação } \\
\text { conceitual. Sua referência é formada por dois números: } \\
\text { o primeiro refere-se ao número de citações ligadas ao } \\
\text { código; e o segundo, ao número de códigos associados. } \\
\text { Os dois números representam, respectivamente, seu } \\
\text { grau de fundamentação (groundedness) e de densidade } \\
\text { teórica (density). }\end{array}$ \\
\hline Notas de análise (Memos) & $\begin{array}{l}\text { Descrevem o histórico da pesquisa. Registram as } \\
\text { interpretações do pesquisador, seus insights ao longo } \\
\text { do processo de análise. }\end{array}$ \\
\hline Esquemas gráficos (Netview) & $\begin{array}{l}\text { Esta ferramenta auxilia a visualização do } \\
\text { desenvolvimento da teoria e atenua o problema de } \\
\text { gerenciamento da complexidade do processo de } \\
\text { análise. Os esquemas gráficos são representações } \\
\text { gráficas das associações entre códigos. A natureza } \\
\text { dessas relações é representada por símbolos. Além } \\
\text { disso, os códigos e as citações são manipuláveis, } \\
\text { podem ser movidas na tela. }\end{array}$ \\
\hline $\begin{array}{l}\text { Comentários } \\
\text { (Comment) }\end{array}$ & $\begin{array}{l}\text { Podem estar presentes em todos os elementos } \\
\text { constitutivos. Devem ser utilizados pelos pesquisadores } \\
\text { para registrar informações sobre seus significados, } \\
\text { bem como para registrar o histórico da importância } \\
\text { do elemento para a teoria em desenvolvimento. }\end{array}$ \\
\hline
\end{tabular}

Fonte: Adaptado de Walter e Bach (2009, p. 8). 
Mediante a questão de pesquisa e os estudos realizados sobre análise de conteúdo, o grupo de pesquisa criou um roteiro de análise, de tal maneira que possibilitasse auxiliar a análise juntamente com o software. Esse roteiro conta com uma análise objetiva, isto é, com a análise de dados genéricos com informações sobre a estrutura dos artigos e catalogação, de maneira que é possível resgatar as informações e utilizar posteriormente alguns desses dados, conforme o quadro 2 .

Quadro 2 - Análise objetiva

\begin{tabular}{|c|c|c|}
\hline \multicolumn{3}{|c|}{ Análise Objetiva } \\
\hline Seq. & O que deve ser buscar na análise & Códigos \\
\hline $\mathbf{1}$ & O resumo & Resumo \\
\hline $\mathbf{2}$ & Autor ou autores do trabalho & Autoria \\
\hline $\mathbf{3}$ & Instituições de origem & Instituição \\
\hline $\mathbf{4}$ & Órgãos de financiamento & Financiamento \\
\hline $\mathbf{5}$ & Formação acadêmica & Formação \\
\hline $\mathbf{6}$ & $\begin{array}{c}\text { Estrutura dos artigos, contendo elementos como introdução, } \\
\text { desenvolvimento e conclusões e referências. }\end{array}$ & Estrutura \\
\hline $\mathbf{7}$ & $\begin{array}{c}\text { Chamada de autores e referências (os autores citados no } \\
\text { corpo do texto são referenciados e vice-versa) }\end{array}$ & $\begin{array}{c}\text { Chamada de } \\
\text { autores }\end{array}$ \\
\hline
\end{tabular}

Fonte: Os autores.

A análise de conteúdo propriamente dita emergiu a partir dos estudos realizados pelo grupo. Assim, pode-se construir e chegar ao quadro 3, no qual apresentamos a codificação geral realizada para o material analisado. Esse quadro está nominado de núcleo 1 porque aborda a pesquisa como um todo que também analisará relatos de experiência, não enfocando as pesquisas, mas as práticas de Modelagem Matemática relatadas. 
Quadro 3 - Pesquisa em Modelagem Matemática na Educação Matemática

\begin{tabular}{|c|c|c|}
\hline \multicolumn{3}{|c|}{$\begin{array}{c}\text { NÚCLEO 1: PESQUISA EM MODELAGEM MATEMÁTICA } \\
\text { NA EDUCAÇÃO MATEMÁTICA }\end{array}$} \\
\hline Seq. & O que deve ser buscar na análise & Código \\
\hline 1 & $\begin{array}{l}\text { Este código deve ser utilizado quando forem apresentados } \\
\text { os elementos e as teorias que fundamentaram o tratamento } \\
\text { dos dados. }\end{array}$ & N1-Análise \\
\hline 2 & $\begin{array}{l}\text { Este código deve ser utilizado exclusivamente para autores } \\
\text { que se referem à metodologia. }\end{array}$ & $\begin{array}{l}\text { N1-Autores } \\
\text { Metodologia }\end{array}$ \\
\hline 3 & $\begin{array}{l}\text { Este código deve ser utilizado exclusivamente para todo } \\
\text { autores referenciados sobre Modelagem Matemática. } \\
\text { Exclusivamente o nome do autor. }\end{array}$ & $\begin{array}{l}\text { N1-Autores } \\
\text { Modelagem }\end{array}$ \\
\hline 4 & $\begin{array}{l}\text { Este código deve ser utilizado para todo autor que não se } \\
\text { referir à modelagem e nem à metodologia. }\end{array}$ & N1-Autores Outros \\
\hline 5 & $\begin{array}{l}\text { Este código deve ser utilizado para os instrumentos e } \\
\text { procedimentos de coleta de dados enunciados nos textos. }\end{array}$ & N1-Coleta \\
\hline 6 & $\begin{array}{l}\text { Este código se refere à natureza ou abordagem da pesquisa, } \\
\text { diferenciando pesquisa quantitativa de qualitativa. O } \\
\text { delineamento refere-se ao tipo de pesquisa: exemplos, } \\
\text { etnográfico, estudo de caso, pesquisa ação, pesquisa } \\
\text { experimental, pesquisa bibliográfica. }\end{array}$ & N1-Delineamento \\
\hline 7 & $\begin{array}{l}\text { Este código deve ser utilizado quando o autor enuncia } \\
\text { explicitamente o objetivo da investigação. Em caso de } \\
\text { dúvida marcar. }\end{array}$ & N1-Objetivo \\
\hline 8 & $\begin{array}{l}\text { Este código deve ser utilizado quando o objeto de } \\
\text { investigação for explicitado pelo autor ou quando da falta } \\
\text { do problema ou de objetivos. }\end{array}$ & N1-Objeto \\
\hline 9 & $\begin{array}{l}\text { Este código deve ser utilizado quando o autor enuncia o } \\
\text { problema em forma de pergunta. }\end{array}$ & N1-Problema \\
\hline 10 & $\begin{array}{l}\text { Este código deve ser utilizado quando o autor enuncia as } \\
\text { etapas e ações desenvolvidas na pesquisa. }\end{array}$ & N1-Procedimento \\
\hline 11 & $\begin{array}{l}\text { Este código deve ser utilizado quando os autores enunciam } \\
\text { o resultado de sua pesquisa. }\end{array}$ & N1-Resultados \\
\hline
\end{tabular}

Fonte: Os autores.

Realçamos que os códigos apresentados nos quadros favoreceram a primeira análise chamada de análise textual, em que buscamos o conteúdo significativo referente às questões nos textos tomados como dados.

\section{Análise dos trabalhos publicados na IV CNMEM}

A IV Conferência Nacional sobre Modelagem na Educação Matemática contou com 27 artigos publicados em comunicações científicas. Os artigos foram 
analisados mediante todas as categorias previamente estabelecidas, apresentadas no quadro 3 .

A maneira como se procedeu à análise incluiu ao menos duas leituras do trabalho e codificação primária, ou seja, uma análise textual para destacar os aspectos buscados no texto. Ressalta-se que a codificação foi conferida por outro pesquisador, o que inclui uma terceira leitura mais pontual acerca da coerência e consistência das codificações. Esse primeiro momento pode ser caracterizado como uma parte da descrição analítica mencionada acima.

A figura 1 permite visualizar como ficou a codificação primária, ou seja, apenas uma análise textual fidedigna ao texto, haja vista que o software recupera, exatamente, o excerto (quote) marcado. A figura também mostra como é a interface do software. $\mathrm{Na}$ janela da esquerda ficam os documentos inseridos para a análise e na da direita as codificações efetuadas sobre o texto. Uma leitura do quadro 1 permite identificar os ícones que aparecem na figura 1 .

\section{Figura 1}

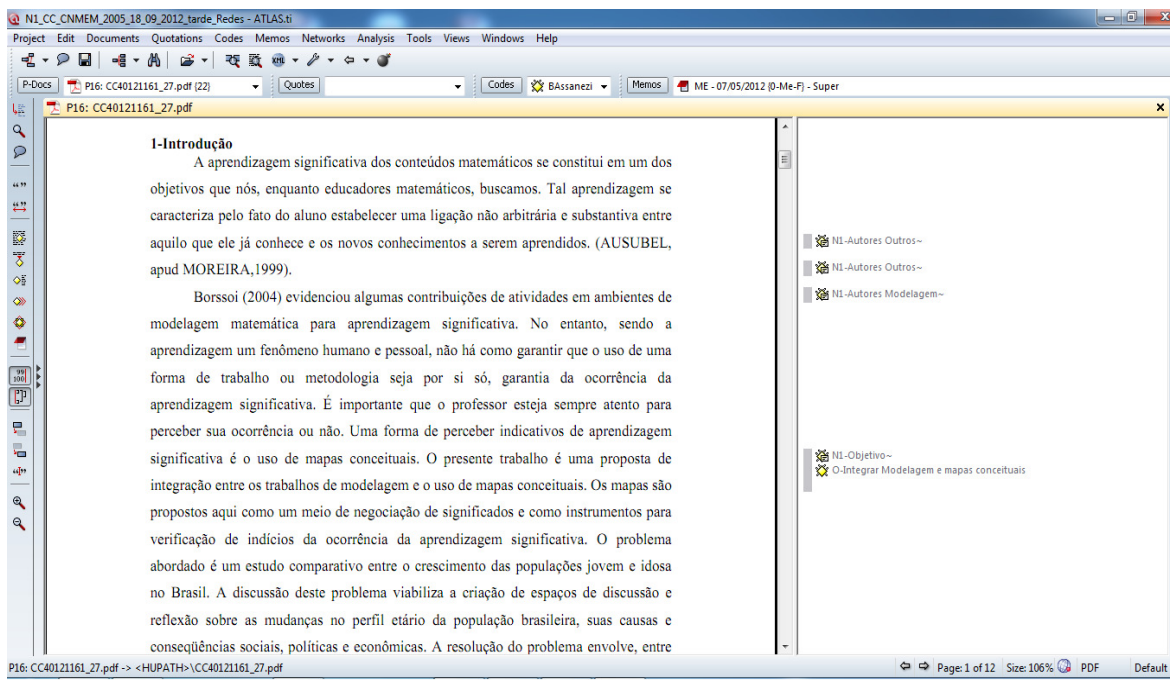

Fonte: Pesquisa dos autores.

Efetuadas todas as codificações, passamos à segunda etapa, que consistiu em interrogar, buscando pelos significados de todos os objetivos, problemas e objetos de pesquisa explicitados nas comunicações científicas. Para tanto recodificamos as citações (quotes), em novos códigos, os quais expressam uma compreensão dos investigadores sobre aqueles códigos. A figura 2 elucida o dito, pois o código "O - Investigar a importância da modelagem na perspectiva etno" é decorrente de uma asserção sobre a citação 26:22, ou seja, a vigésima segunda 
citação no vigésimo sexto documento primário. A flecha indica que o código e a citação estão interligados (link).

Figura 2

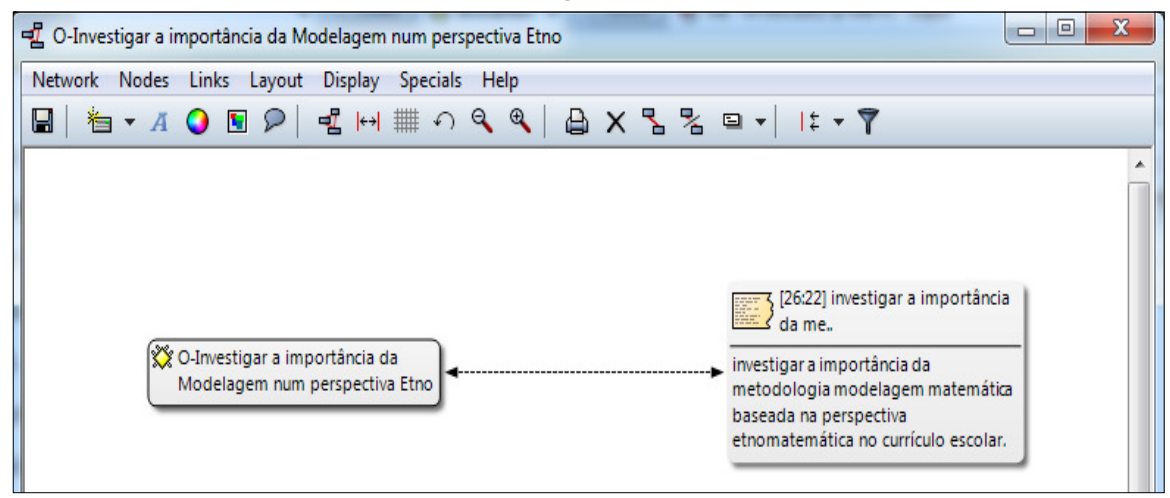

Fonte: Pesquisa dos autores.

Observe-se que poderíamos ter passado à reunião dos significados diretamente, mas optamos por essa recodificação por entender que ela expressa um rigor acerca do qualitativo, quando se busca uma compreensão refletida sobre o codificado. Observe-se, também, que ao transformar a citação em código, torna-se mais fácil e menos poluído, visualmente, o trabalho de categorização que é imediatamente posterior. Para a categorização questionamos: qual o tema mais abrangente, além de particularidades, que se mostram a partir dos significados dos códigos? Esse procedimento sustentou a análise que conduziu às categorias, as quais dizem sobre o significado articulado das citações. Estas categorias serão apresentadas em figuras, com uma breve descrição de como foram estabelecidas, de maneira semelhante ao realizado na tese de Klüber (2012).

Inicialmente foram codificados 45 objetivos e 8 problemas de pesquisa, enunciados explicitamente nas comunicações científicas, num total de 53 códigos. Na releitura, quando do processo de categorização, permaneceram apenas 48 códigos entre objetivos e problemas, e o objeto de pesquisa não apareceu escrito de maneira explícita nos textos. Nesse momento consideramos adequado destacar que o software permite refinar as primeiras análises quando se avança para análises conceituais, pois é possível resgatar a totalidade dos dados. Com as codificações (codes), essas citações, unidades destacadas dos textos, foram reunidas em quatro categorias, que se articulam e expressam núcleos de investigação sobre Modelagem Matemática na Educação Matemática, quais sejam: 1) Metaestudo em Modelagem Matemática; 2) Aplicação de modelagem; 3) Articulação entre modelagem e outras teorias; 4) Modelagem e formação de professores. 
Na próxima seção expomos as categorias e a análise inferencial, buscando explicitar os seus significados para os objetivos, objetos e problemas de pesquisa em Modelagem Matemática na Educação Matemática.

\section{Da análise inferencial}

A categoria apresentada por meio da figura 3, denominada de Metaestudo em Modelagem Matemática, foi constituída a partir das citações (quotes) 2.7, 11.1, 11.7 e 19.4. Contempla algumas das perspectivas possibilitadas pela Modelagem Matemática nos trabalhos analisados e que vão além de sua mera aplicação. Compõem esse núcleo aspectos que envolvem o conceito de cidadania como um objetivo da Modelagem Matemática e investigações sobre outras pesquisas realizadas por um grupo de pesquisa.

\section{Figura 3}

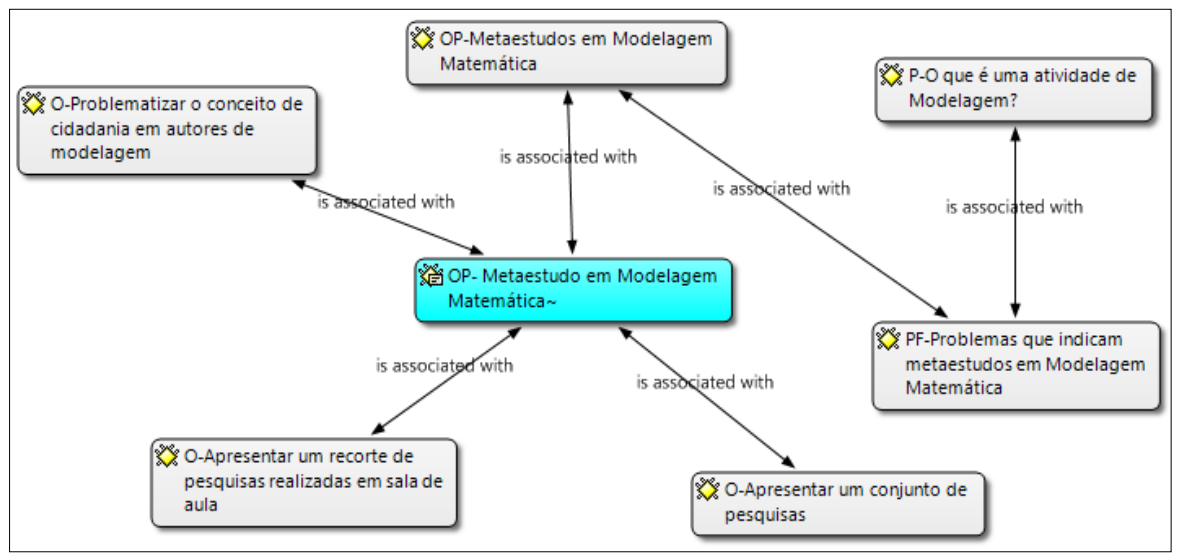

Fonte: Pesquisa dos autores.

Numa primeira interpretação acerca do conceito de cidadania, pode-se dizer que possui um contexto histórico em que se ampara, como por exemplo, na constituição de 1988, denominada pelo presidente da comissão constituinte de "Constituição Cidadã". Tal denominação deve-se à preocupação com o desenvolvimento da cidadania, o qual, segundo o mesmo documento, pode ser alcançado por meio da educação, concebida como instrumento. $O$ documento ressalta que a principal finalidade da educação "é o seu preparo para a cidadania e sua qualificação para o trabalho", conforme art. 205 da constituição federal, ao tratar da ordem social e, reiterado pela Lei de Diretrizes e Bases da Educação Nacional (BRASIL, 1996). Em termos educacionais, os Parâmetros Curriculares Nacionais (BRASIL, 1997a, 1997b), ao tratar especificamente da Matemática, 
colocam-na como uma componente importante nesse tipo de formação. Contudo, que matemática trabalhada na escola favorece elementos que ajudam a formar cidadania: a matemática repetitiva, memorizada, a matemática das listas dos exercícios mecânicos? A matemática sem sentido, sem contexto e sem significado? Parece ser nesse contexto que a Modelagem Matemática, como um modo de trabalhar com matemática, emerge.

No entanto, frente a esses elementos, compreendemos que não é a adoção da Modelagem, por si só, capaz de garantir a formação cidadã dos nossos jovens estudantes. Por um lado, a adoção de metodologias que promovam, no estudante, a criatividade, a autonomia, à compreensão dos símbolos e significados, a capacidade de trabalhar em grupo, desenvolver a segurança, tem ganhado adeptos no ensino de Matemática. A Modelagem pode ser uma forma e, por isso, tem sido estudada e desenvolvida em âmbito escolar, em aulas. Por outro lado, estudos como estes remetem aos significados de conceitos que são utilizados, muitas vezes, sem muita reflexão para a área. Afirmamos isso porque a cidadania não é um conceito homogêneo e pode variar de sociedade para sociedade, conforme situações econômicas, sociais e culturais. Indo além da pesquisa apresentada, é possível afirmar que um metaestudo como este indica possibilidades de investigação sobre conceitos tidos como consolidados no âmbito da Modelagem Matemática. Em outras palavras, permite voltar-se para aspectos da constituição da Modelagem na Educação Matemática, no tocando ao contexto social e econômico brasileiro. O que se levanta aqui é a urgência de estudos que enfrentem problemas pontuais como a noção de contexto, crítica e motivação, que são recorrentes no âmbito da Modelagem, mas que ainda não foram enfrentados de maneira mais profunda.

Outra perspectiva que se inclui nessa categoria e que se constitui um objetivo é aquela que utiliza outras teorias e tecnologias para desenvolver a modelagem em sala de aula. Assim, as pesquisas que incluem a tecnologia nos trabalhos com a modelagem ganham relevância na medida em que se inserem outras áreas do conhecimento, tais como meio ambiente e biologia, além de promover uma possibilidade de socialização na chamada formação do professor em serviço, nas modalidades de educação a distância. Essas pesquisas, denominadas tecnologias da informação e comunicação (TIC), têm sido conduzidas, na maioria das vezes, pelos grupos de pesquisas das instituições de Ensino Superior. Nos últimos anos têm sido crescente a interação entre modelagem e tecnologia da informação e da comunicação nas várias etapas da formação docente: iniciação científica, na pós-graduação. Pesquisadores têm articulado trabalhos de naturezas diversas com a modelagem, como a experiência realizada por Borba e Penteado (2001), na qual buscaram integrar o trabalho de experimentação com tecnologia ao trabalho de modelagem. 
Em linhas gerais essa categoria indica para um movimento de reflexão e pesquisa possível na comunidade da Modelagem Matemática na Educação Matemática: refletir sobre a sua própria produção. Apesar de este estudo ser parcial, pois, como explicitamos, analisaremos também outras edições mais recentes do evento, essa categoria aponta para uma demanda da área. Investigações como esta devem ser desenvolvidas com a intenção de produzir resultados que permitam repensar a dinâmica das pesquisas, os temas por ela já desenvolvidos e também para pensar em outros temas que podem ser tratados olhando a própria pesquisa. Dito de outro modo, oferecer uma caracterização que permita aos pesquisadores repetirem investigações em níveis mais elementares, como a graduação e pós-graduação lato sensu, $e$ efetuarem novas investigações em níveis em que se exige isso, como a pós-graduação stricto sensu.

A categoria mostrada na figura 4, Aplicação da Modelagem Matemática, foi estabelecida a partir das citações (quotes) a seguir: 23.21, 23:15, 24:14, 23:12, 12:21, 12:19, 23:14, 4:9, 15:4, 23:10, 4:4, 8:27, 24:13, 1:21, 23:11, 18:1, 15:3, 8:9, 4:6, 23:9. Essas citações, que se transformaram nos códigos apresentados na figura, referem-se aos objetivos de aplicação da Modelagem Matemática. Os objetivos buscam desde a verificação de resultados da literatura à aplicação em diversos contextos.

Figura 4

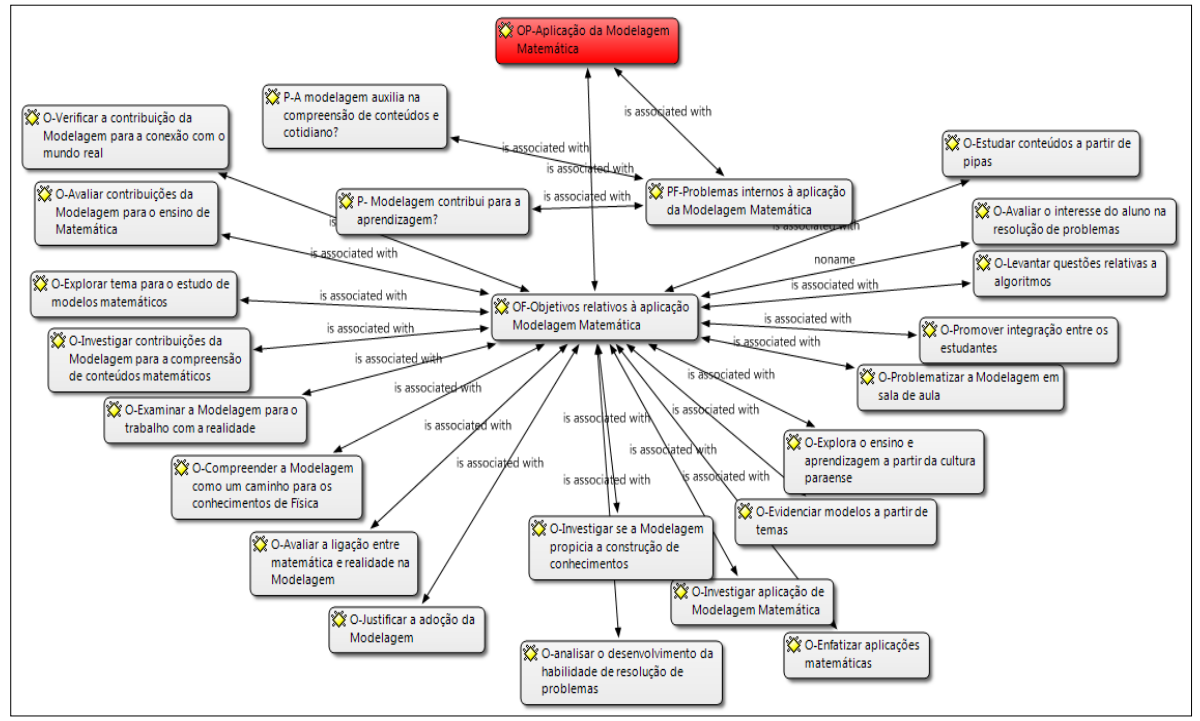

Fonte: Pesquisa dos autores.

Nessa categoria podem ser identificados alguns problemas de pesquisa escritos explicitamente. Ressaltamos que essa não é uma característica muito 
comum nos trabalhos em geral. No que concerne à redação, há a predominância da apresentação de objetivos, o que em muitos casos dificulta a compreensão do objeto e do problema propriamente dito, indo ao encontro, parcialmente, daquilo que já foi explicitado por Araújo (2009). Numa análise dos verbos que indicam as ações investigativas, destacam-se: verificar (contribuição, auxílio ou construção da aprendizagem), avaliar, explorar ou levantar (tema ou modelo), trabalhar (com conteúdos e a própria modelagem), examinar, enfatizar, justificar (sobre a utilização da modelagem).

Esse tipo de investigação é relatado na literatura como o mais recorrente nas pesquisas sobre Modelagem Matemática, conforme Barbosa (2001), Araújo (2009) e Bicudo e Klüber (2011). Por um lado, ele representa uma importante faceta das investigações, pois pode indicar a iniciação à pesquisa no assunto, por pessoas que ainda não tenham desenvolvido pesquisa. Expressa, ainda, uma necessidade dos professores de matemática da Educação Básica que, geralmente, não participam de núcleos de pesquisa de Modelagem Matemática. Nesse sentido, são impelidos a realizarem investigações mais voltadas à verificação e à confirmação de resultados da literatura sobre o tema. Essa afirmação, em certo sentido, contradiz Araújo (2009, p. 7) que sustenta: "A repetição dos temas investigados vai de encontro à noção de pesquisa apresentada por Niss (2001): as perguntas colocadas não são genuínas e, talvez, já existam "respostas" satisfatórias para elas no campo". Mesmo que essa afirmação tenha um significado, ela não alcança diferentes correntes epistemológicas, por exemplo, aquelas que queiram confirmar resultados para quem não é iniciado na pesquisa. Além disso, os resultados em ciências humanas e sociais não podem ser tomados como resultados idênticos aos das ciências naturais, com sentido de prova. E, por fim, há que se considerar o alcance dos resultados de pesquisa e os modos que eles podem ser interpretados pelos não iniciados no campo de estudos.

Por outro lado, pode indicar, ainda, a extensão de uma tradição de pesquisa oriunda a Matemática Aplicada, de acordo com Klüber e Burak (2012). O termo extensão é empregado aqui, em acepção, àquele cunhado por Fleck, que denota, depois da instauração de um estilo de pensamento, a sua disseminação, consolidação e extensão (expansão). Dito de outro modo, a Modelagem Matemática na Educação Matemática se instaura em um estilo de pensamento - conjunto de teorias e práticas de especialistas em uma área - decorrente da Matemática Aplicada, como explicitado em Klüber (2009) ${ }^{4}$. Assim, torna-se bastante forte o significado de aplicação da Modelagem Matemática em consonância com as aplicações de Matemática. Como essa é uma prática comum entre os pesquisadores

\footnotetext{
${ }^{4}$ Para maiores aprofundamentos sobre o tema, remetemos o leitor para o referido artigo que consta nas referências bibliográficas.
} 
da Matemática Aplicada, ela passa a ser uma prática socialmente legítima para os que não são iniciados, pois, de acordo com a teoria fleckiana, o grupo de especialistas, por meio do estilo de pensamento, tende a formatar a maneira de agir dos iniciantes. A tradição epistemológica da aplicação é transferida para a Educação Matemática. Assim os problemas tendem a centrar-se na aplicação propriamente dita da Modelagem, na obtenção dos modelos e na organização matemática necessária à atividade. Decorridas mais de três décadas essa característica ainda é bastante acentuada, talvez pelo perfil dos orientadores que ainda são epistemológica e metodologicamente orientados pelas aplicações de matemática, sem diálogo intenso com teorias da Educação e Educação Matemática.

Compreendemos que esses trabalhos também emergem com força, por conta de a publicação ser em evento. Com isso não dizemos que os eventos não possuam critérios, mas que pesquisas iniciais e mesmo exploratórias podem ser publicadas nestes eventos, o que, ao menos em tese, não ocorre em revistas em que o processo é reconhecidamente mais lento, portanto, feito com mais aprofundamento. Essa é outra interpretação que em certo sentido vai de encontro às interpretações de Araújo (2009) que também focou eventos em suas análises.

No sentido de dar contribuições compreendemos que esses temas de pesquisa são importantes, mas que a tematização sobre eles mesmos se impõe, como, por exemplo: como se dá o estudo de conteúdos a partir da Modelagem Matemática? Questões teóricas sobre como os alunos aprendem esses conteúdos a partir da modelagem, há particularidades? Existem impactos cognitivos e afetivos que podem ser comprovados mediante dados empíricos? Existem procedimentos próprios da modelagem para o trabalho em sala de aula, para além daqueles amplamente reconhecidos entre os matemáticos aplicados ou mesmo de procedimentos gerais de cunho didático-pedagógico? Esses exemplos têm a função de provocar reflexões para que mais questões como essas sejam investigadas. Contudo, essa característica convive com um processo de transformação na pesquisa em Modelagem, o que pode ser identificado na categoria que articula modelagem e outras teorias, a qual é explicitada subsequentemente.

A categoria em destaque na figura 4, denominada Articulações entre a Modelagem Matemática e outras teorias, foi constituída a partir dos significados de expressões nas citações: 10:28, 18:2, 6:7, 6:8, 6:9, 6:10, 11:9, 26:22, 14:3, 10:1, 13:4, 15:2, 16:4, 20:3, 27:10, 22:1, 27:9, 21:2, 27:7 e 27:8. Em linhas gerais, são objetivos que buscam agregar aspectos teóricos e educacionais à Modelagem Matemática, estabelecendo novos objetos de investigação. 


\section{Figura 5}

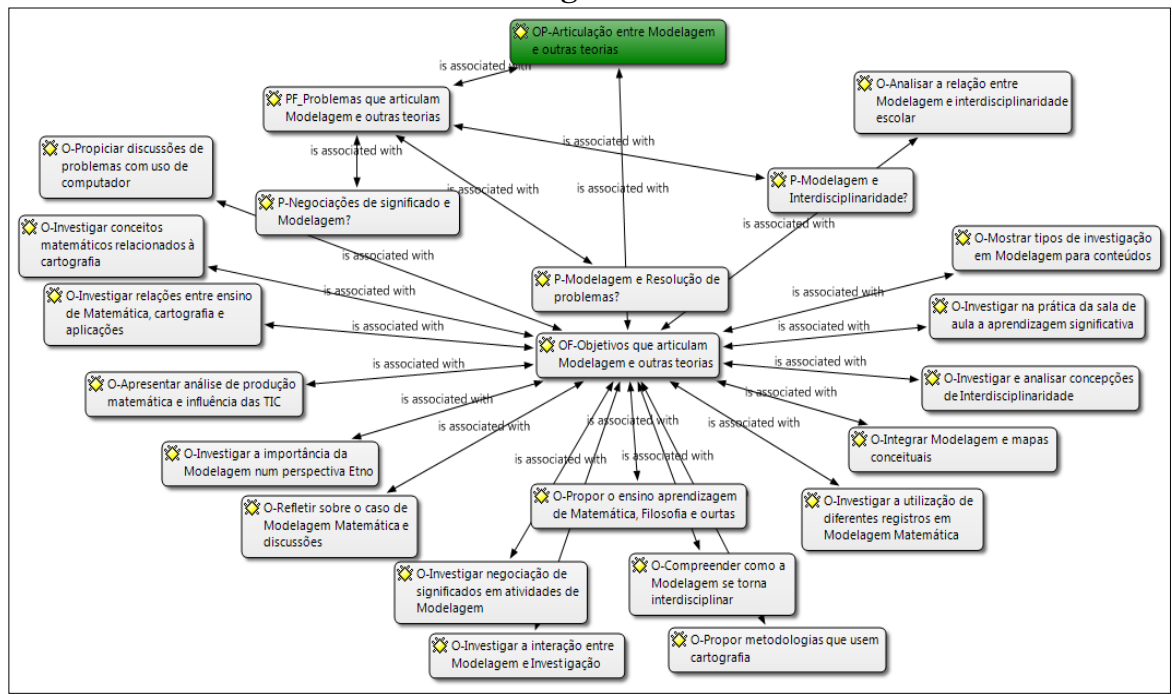

Fonte: Pesquisa dos autores.

Por meio de uma análise dos códigos mostrados na figura acima, os distintos escopos de articular a modelagem no seu fazer, tais como avaliar, compreender, examinar, investigar, enfatizar, entre outros, mostram um movimento que busca vincular as atividades de Modelagem Matemática, de forma mais efetiva, ao campo da Educação Matemática, pois, ao considerar os objetivos expressos nas citações, denotam-se objetivos que propõem articular algumas teorias de aprendizagem; teorias que se constituem tendências em Educação Matemática e mesmo em outros campos de estudo. Constata-se, portanto, um movimento da comunidade na superação de uma frágil concatenação, entre Modelagem Matemática e aprendizagem matemática. Buscar articulações com outras teorias significa buscar relações coerentes, formas de unir duas teorias, duas tendências e procurar respostas que ofereçam sentido e coerência ao fazer modelagem.

A intenção de superar as conexões que se fazem, ainda frágeis em muitos momentos, deve conduzir às reflexões e possibilitar novos estudos, novas investigações, novas práticas, tendo como estofo as várias teorias e resultados correlacionados à modelagem. Destaque-se que há aproximações, ainda que, nesta fase, tênues entre a modelagem e teorias de aprendizagem, tais como a Aprendizagem Significativa de David Ausubel (1968), a Teoria das Representações Semióticas de Raymond Duval (2003) no ensino de Matemática mediado pela Modelagem Matemática. Outra constatação nos objetivos e problemas analisados é a aproximação da Modelagem com a tendência denominada Investigação Matemática de acordo com Ponte; Brocardo e Oliveira (2005), a incorporação gradativa das 
tecnologias da informação e da comunicação nos trabalhos de Borba e Penteado (2001), Borba e Villarreal (2005), que buscam articular, em suas práticas e pesquisas, a experimentação e a tecnologia, utilizando a modelagem como uma mediação de outras áreas para o ensino de Matemática, ora valendo-se dessas tendências para mediar o trabalho, ora utilizando-a para viabilizar o trabalho com essas tendências.

Assim, o que se busca na articulação do trabalho com a Modelagem e outras áreas é uma maior compreensão de como isso se conduz no interior de uma prática de modelagem, em que se pretende uma compreensão maior dos significados presentes nas ações de modelagem, para o que se impõe uma necessidade de efetuar incursões na Epistemologia, nas teorias da aprendizagem e nas Representações Semióticas, na Filosofia incluem, ainda, outras tendências em Educação Matemática, como as já mencionadas. Pode evidenciar, em certo sentido, a falta de alguns elementos no âmbito da própria Modelagem, no tocante ao ensino e à aprendizagem de conteúdos matemáticos.

Os trabalhos da IV Conferência Nacional Sobre Modelagem na Educação Matemática indicam alguns avanços que se esperam ver consolidados nas análises dos outros eventos; porém, mesmo não sendo o foco deste artigo, é possível afirmar que muitos desses objetivos não se consolidam, porque a teorização que articula Modelagem e outras teorias tende a não ser alcançada ou esclarecida no texto, em termos de resultados.

Desse modo, mesmo que a perspectiva se faça presente com as incursões de outras áreas do conhecimento, percebe-se, ainda, um fazer mais voltado à confirmação do que propriamente para analisar e compreender articulações que exigem uma postura diferente de interrogar o objeto de estudo. É também plenamente compreensível essa maneira de conduzir a pesquisa, pois essa busca se faz por muitos professores da Educação Básica e, também por pesquisadores orientados por uma visão epistemológica que ainda não está superada, uma vez que participam de um círculo que compreende a Modelagem a partir da tradição da Matemática Aplicada.

A categoria mostrada na figura 6, Modelagem e formação de professores, foi estabelecida a partir da articulação dos significados das citações 1:20, 5:3, 9:3 e 25:6. Essas citações se referem a objetivos pontuais, que buscam compreender aspectos da inserção da Modelagem Matemática na formação de professores de Matemática. Esses objetivos concernem aos saberes produzidos, à prática da modelagem, às impressões ou compreensões dos professores sobre modelagem, em diferentes situações e contextos escolares. 
Figura 6

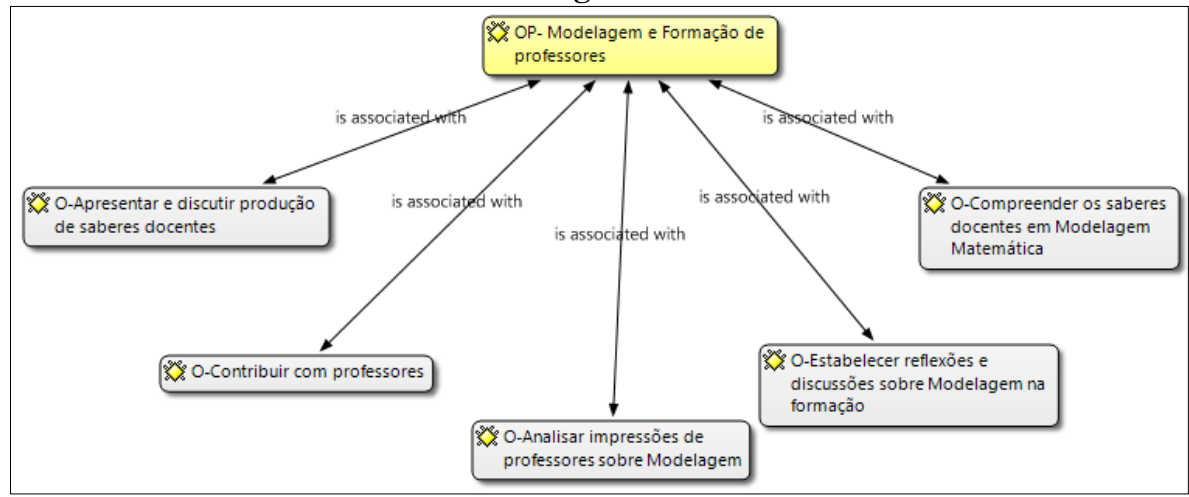

Fonte: Pesquisa dos autores.

A primeira afirmação que podemos fazer é que o número de objetivos com a pretensão de articular modelagem e formação de professores, nesta edição da CNMEM, ainda é tímido, da mesma maneira que para a categoria metaestudos. Em se tratando do significado dos objetivos de pesquisa, constata-se que eles já foram abordados de alguma forma em outras investigações, como a de Barbosa (2001), que enfocou o que pensavam professores de Matemática sobre modelagem. Em linhas gerais, estas investigações mostram uma preocupação similar, ou seja, com as implicações da Modelagem Matemática na formação de professores. Implicitamente, concebe-se que a modelagem é uma prática diferenciada, por isso a sua utilização, em diferentes contextos, pode ocasionar mudanças de prática e produção de distintos saberes, bem como desconfortos pelos mesmos motivos.

Faz-se importante uma análise dos verbos que caracterizam essas investigações, quais sejam: analisar, apresentar, discutir e compreender. O uso desses verbos indica distintos modos de efetuar a pesquisa. Em alguns momentos, eles revelam características mais pontuais, referentes mesmo ao artigo ou à apresentação dos resultados; em outros, indicam apenas objetivos intermediários, como é o caso de analisar e discutir, que são objetivos metodológicos ou internos a uma prática específica de sala de aula, numa classificação próxima àquela indicada por Larocca; Rosso e Souza (2005). E, por fim, representam também objetivos mais amplos, expressados pelo verbo compreender que, implicitamente, solicita a explicitação dessa compreensão.

Esses objetivos se mostram significativos para a área, pois alcançam uma demanda da disseminação daquilo que é considerado pertinente em modelagem. No entanto, há que se questionar sobre o tempo destinado a essas investigações, que, em sua maioria, não são de longo prazo, ou, se são, não são informadas nos artigos publicados. 
Sem dúvida, este tema "Modelagem Matemática e formação de professores" deve estar na pauta das investigações realizadas pela comunidade, mas a própria comunidade pode pensar sobre outras questões como: quais os aspectos que caracterizam o confronto cultural e acadêmico entre a Modelagem Matemática e formação de professores de Matemática? Que investigações podem decorrer dessa caracterização? Mesmo que essa categoria se refira exclusivamente aos objetivos de investigações apresentadas em 2005, ele congrega em si significados mais abrangentes, que poderão ser confirmados quando empreendermos a análise das demais edições. Dessa categoria ficam as pistas para um olhar mais detido e consistente para as demais produções que articulam modelagem e formação de professores como um tema de suma importância para a comunidade.

\section{Apontamentos e possibilidades de investigação}

Como é possível acompanhar no decorrer do texto, quatro grandes categorias foram apresentadas, as quais, segundo nossa compreensão, descrevem, a partir dos seus significados, os focos dos objetivos, objeto e problemas de pesquisa. A título de ilustração e síntese, inserimos o quadro 5 que contém as citações que permitiram a construção das categorias e uma rápida explanação sobre os significados dessas categorias.

Quadro 4 - Síntese das categorias elencadas

\begin{tabular}{|c|c|c|}
\hline Categorias & Citações (quotes) & Principal significado \\
\hline $\begin{array}{l}\text { Metaestudo em } \\
\text { Modelagem } \\
\text { Matemática }\end{array}$ & $2.7,11.1,11.7$ e 19.4 & $\begin{array}{l}\text { Objetivos que buscam transcender } \\
\text { fazeres internos à Modelagem } \\
\text { Matemática }\end{array}$ \\
\hline $\begin{array}{l}\text { Aplicação de } \\
\text { Modelagem }\end{array}$ & $\begin{array}{c}\text { 23.21, } 23: 15,24: 14,23: 12,12: 21 \\
\text { 12:19, } 23: 14,4: 9,15: 4,23: 10 \\
\text { 4:4, 8:27, 24:13, 1:21, 23:11, } \\
\text { 18:1, 15:3, 8:9, 4:6, 23:9 }\end{array}$ & $\begin{array}{l}\text { Objetivos que buscam aplicar } \\
\text { Modelagem em diferentes } \\
\text { contextos e confirmar situações } \\
\text { relatadas na literatura }\end{array}$ \\
\hline $\begin{array}{l}\text { Articulação entre } \\
\text { Modelagem e } \\
\text { outras teorias }\end{array}$ & $\begin{array}{c}10: 28,18: 2,6: 7,6: 8,6: 9,6: 10 \\
11: 9,26: 22,14: 3,10: 1,13: 4 \\
15: 2,16: 4,20: 3,27: 10,22: 1 \\
27: 9,21: 2,27: 7,27: 8\end{array}$ & $\begin{array}{l}\text { Objetivos que buscam articular } \\
\text { Modelagem Matemática e outras } \\
\text { teorias para subsidiar aprendizagem } \\
\text { em matemática e mesmo } \\
\text { potencializar outras tendências em } \\
\text { Educação Matemática }\end{array}$ \\
\hline $\begin{array}{l}\text { Modelagem e } \\
\text { formação de } \\
\text { professores }\end{array}$ & $1: 20,5: 3,9: 3,25: 6$ & $\begin{array}{l}\text { Objetivos de pesquisa que focam } \\
\text { as implicações da inserção da } \\
\text { Modelagem no âmbito da formação } \\
\text { de professores de Matemática. }\end{array}$ \\
\hline
\end{tabular}

Fonte: Os autores. 
Essas categorias ficam abertas para a articulação dos resultados das análises dos demais eventos que congregam a investigação maior. Elas se constituem em ponto de partida e permitem uma compreensão temporalizada das pesquisas para o evento que analisamos. Com o desenrolar da pesquisa, esperamos ter condições de situar de maneira mais consistente os núcleos de investigação que vem ocorrendo no âmbito da Modelagem Matemática na Educação Matemática, a partir da totalidade dos dados.

No entanto, consideramos pertinente apontar alguns focos de investigação que se abrem para cada categoria e que precisam ser debatidos e refinados perante a comunidade: 1) É necessário investir em mais estudos de tipo meta-analítico? Quais? 2) Quando se trata de aplicações de modelagem, o que elas representam e para que grupo é mais consistente? Essas aplicações são interferidas pelas distintas perspectivas de modelagem? Se isso ocorre, em que medida os grupos de pesquisa que concebem a modelagem de maneiras distintas podem estar influenciando aplicações que parecem repetições, mas, também, podem ser aplicações de distintas perspectivas? Quais os enfoques e como as teorias reconfiguram as práticas de modelagem?

Em se tratando de aprendizagem, não emergiram estudos que sejam metodologicamente orientados, construídos na relação teoria/objeto de estudo que indiquem a aprendizagem matemática com modelagem. Mesmo que isso se tenha iniciado com a tentativa da articulação da Modelagem e Registros de Representação Semiótica, por exemplo, em última instância, caberia perguntar sobre uma perspectiva de modelagem orientada pelas representações semióticas. Entenda-se o mesmo, analogamente, para outras teorias. Assim, esse parece ser um tema importante a ser enfrentado.

Por fim, a formação de professores em Modelagem Matemática exige reflexões que superam uma visão epistemológica de linearidade, ou seja, "daqui para frente"; carece, portanto, de reflexões situadas que considerem toda a trajetória docente, além de esta questão estar relacionada à aprendizagem com modelagem para aqueles que desejam assumi-la. Sem dúvida, conhecemos, a partir de nossas vivências, algumas investigações que têm tentado enfrentar essa problemática, como a realizada por Oliveira e Barbosa (2007a, 2007b), que trata das tensões dos professores ao realizar a primeira experiência com modelagem. Porém, novos caminhos precisam ser trilhados para o fortalecimento da comunidade.

\section{Referências}

ALMEIDA, L. M. W. de. Algumas reflexões sobre a pesquisa em Modelagem Matemática. In: SEMINÁRIO INTERNACIONAL DE PESQUISA EM EDUCAÇÃO MATEMÁTICA, 3., 2006, Águas de Lindóia. Anais... Curitiba: SBEM, 2006. p. 1-12. 
ARAÚJO, J. L. Pesquisas sobre Modelagem em eventos científicos recentes de Educação Matemática no Brasil. In: SEMINÁRIO INTERNACIONAL DE PESQUISA EM EDUCAÇÃO MATEMÁTICA, 4., 2009, Taguatinga. Anais... Taguatinga: UCB, 2009. p. 1-14.

AUSUBEL, D. P. Educational psychology: a cognitive view. New York: Holt; Rinehart and Winston, 1968.

BARBOSA, J. C. Modelagem Matemática: concepções e experiências de futuros professores. 2001. 253 f. Tese (Doutorado em Educação Matemática) - Instituto de Geociências e Ciências Exatas, Universidade Estadual Paulista, Rio Claro, 2001.

. Sobre a pesquisa em Modelagem Matemática no Brasil. In: CONFERÊNCIA NACIONAL SOBRE MODELAGEM NA EDUCAÇÃO MATEMÁTICA, 5., 2007, Ouro Preto, Anais... Ouro Preto: Universidade Federal de Ouro Preto/Universidade Federal de Minas Gerais, 2007. p. 82-103.

BARBOSA, J. C.; ARAÚJO, J. de L.; CALDEIRA, A. D. GT 10 - Modelagem Matemática: relatório das sessões do GT10 no IV SIPEM. SBEM, 2009. Disponível em: < http://www. sbem.com.br/gt10/pdf/relatorio_ivsipem.pdf> Acesso em: 09 jul. 2011.

BARDIN, L. Análise de Conteúdo. Lisboa, Portugal: Edições 70, 1977.

BICUDO, M. A. V.; KLÜBER, T. E. Pesquisa em Modelagem Matemática no Brasil: a caminho de uma metacompreensão. Cadernos de Pesquisa, São Paulo, v. 41, n. 144, p. $902-$ 925, set./dez. 2011. DOI: 10.1590/S0100-15742011000300014

BORBA, M. C.; PENTEADO, M. G. Informática e Educação Matemática. Belo Horizonte: Autêntica, 2001.

BORBA, M. C.; VILLARREAL, M. E. Humans-with-Media and reorganization of Mathematical thinking: information and communication technologies, modeling, visualization and experimentation. New York: Springer Science + business Media, Inc, 2005.

BRASIL. Constituição da República Federativa do Brasil. Brasília: Senado, 1988.

Lei 9.394, de 20 de dezembro de 1996. Estabelece as Diretrizes e Bases da Educação Nacional. Diário Oficial da União, Brasília, v. 134, n. 248, p. 27833-841, 23 dez. 1996.

. Ministério da Educação. Secretaria de Educação Média e Tecnológica. Parâmetros curriculares nacionais para o ensino fundamental. Brasília: MEC/SEMTEC, 1997a.

. Ministério da Educação. Secretaria de Educação Média e Tecnológica. Parâmetros curriculares nacionais para o ensino médio. Brasília: MEC/SEMTEC, 1997b.

DUVAL, R. Registros de representações semióticas e funcionamento cognitivo da compreensão em matemática. In: MACHADO, S. D. A. Aprendizagem em Matemática: registros de representação semiótica. Campinas: Papirus, 2003. p. 11-34.

FLECK, L. La génesis y el desarrollo de un hecho científico. Prólogo de Lothar Schäfer e Thomas Schenelle. Madrid: Alianza Universidad, 1986.

FRANCO, M. L. P. B. Análise de conteúdo. 2. ed. Brasília: Líber livro, 2005. (Série Pesquisa). KLÜBER, T. E. Um olhar sobre a Modelagem Matemática no Brasil sob algumas categorias fleckianas. Alexandria, Florianópolis, v. 2, n. 2, p. 219-240, jul. 2009. 
Uma metacompreensão da Modelagem Matemática na Educação Matemática. 2012,.396 f. Tese (Doutorado em Educação Científica e Tecnológica) - Centro de Ciências Físicas e Matemática, Universidade Federal de Santa Catarina, Florianópolis, 2012. KLÜBER, T. E. ; BURAK, D. Sobre a Pesquisa Qualitativa na Modelagem Matemática em Educação Matemática. Bolema, Rio Claro, v. 26, n. 43, p. 111-133, 2012.

LAROCCA, P.; ROSSO, A. J.; SOUZA, A. P. A formulação de objetivos de pesquisa na pós-graduação em Educação: uma discussão necessária. Revista Brasileira de Pós-Graduação, Brasília, v. 2, n. 3, p. 118-133, mar. 2005. Disponível em: < http://www2.capes.gov.br/rbpg/ images/stories/downloads/RBPG/vol.2_3_mar2005_/118_133_formulacao_objetivos_ pesquisa_posgraduacao_educacao.pdf> Acesso em: 10 mar. 2012.

NISS, M. Issues and problems of research on the teaching and learning of applications and modelling. In: MATOS, J. F.; BLUM, W.; HOUSTON, S. K.; CARREIRA, S. P. (Eds.). Modelling and mathematics education - ICTMA 9: applications in science and technology. Chichester: Horwood Publishing, 2001. p. 72-88.

OLIVEIRA, A. M. P; BARBOSA, J. C. A primeira experiência de Modelagem Matemática e a tensão do "próximo passo". In: ENCONTRO NACIONAL DE EDUCAÇÃO MATEMÁTICA, 9., 2007, Belo Horizonte. Anais... Belo Horizonte: SBEM, 2007a. p. 1-17.

. As situações de tensão e as tensões na prática de Modelagem: o caso Vitória. In: CONFERÊNCIA NACIONAL SOBRE MODELAGEM NA EDUCAÇÃO MATEMÁTICA, 5., 2007, Ouro Preto. Anais... Ouro Preto: Universidade Federal de Ouro Preto e Universidade Federal de Minas Gerais, 2007b. p. 191-206.

PONTE, J. P., BROCARDO, J.; OLIVEIRA, H. Investigações matemáticas em sala de aula. Belo Horizonte: Autêntica, 2005. (Coleção Tendências em Educação Matemática).

TRIVIÑOS, A. N. S. Introdução à pesquisa em ciências sociais. 16. reimp. São Paulo: Atlas, 2008.

WALTER, S. A.;BACH, T.M. Adeus papel, marca-textos, tesoura e cola:Inovando o processo de análise de conteúdo por meio do Atlas. In: SEMINÁRIOS DE EMPREENDENDORISMO E EDUCAÇÃO, 12., 2009, São Paulo. Anais... São Paulo: USP, 2009, p. 1-17.

\section{Material Analisado}

CONFERÊNCIA NACIONAL SOBRE MODELAGEM NA EDUCAÇÃO MATEMÁTICA, 4., 2005, Feira de Santana. Anais... Feira de Santana: UEFS, 2005.

Recebido em 31/03/2012

Aceito em 10/09/2012 